\title{
Pengaruh Gaya Kepemimpinan, Motivasi dan Lingkungan Kerja Terhadap Semangat Kerja Karyawan Dinas Perhubungan Kabupaten Gianyar
}

\author{
Tjokorda Istri Dharmayanti ${ }^{1}$ \\ I Gede Putu Kawiana ${ }^{2}$ \\ I Made Astrama ${ }^{3}$ \\ ${ }^{1,2,3}$ Fakultas Ekonomi Bisnis dan Pariwisata Universitas Hindu Indonesia \\ Email : cokgung33@gmail.com
}

Disetujui: 21 Desember 2020

\begin{abstract}
Good HR management is the key to the successful achievement of organizational goals. To increase employee morale there are also other factors that affect employee morale, namely motivation and work environment. The purpose of this study was to determine the effect of leadership style, motivation, and work environment on employee morale of the Gianyar Regency Transportation Agency partially and simultaneously. The sample used was 100 respondents. The data analysis technique used is Multiple Linear Regression. Based on the research results it can be seen that: (1) leadership style has a significant positive effect on employee morale, (2) motivation has a significant positive effect on employee morale, (3) work environment has a significant positive effect on employee morale, and (4) simultaneously leadership style, motivation and work environment have a significant effect on employee morale
\end{abstract}

Key words : leadership style, motivation and work environment on morale

\section{ABSTRAK}

Pengelolaan SDM yang baik merupakan kunci sukses tercapainya tujuan organisasi. Untuk meningkatkan semangat kerja karyawan adapula faktor lain yang mempengaruhi semangat kerja karyawan yaitu motivasi dan lingkungan kerja. Tujuan penelitian ini adalah untuk mengetahui pengaruh gaya kepemimpinan, motivasi, dan lingkungan kerja terhadap semangat kerja karyawan Dinas Perhubungan Kabupaten Gianyar secar aparsial dan simultan. Sampel yang digunakan sebanyak 100 responden. Teknik analisis data yang digunakan adalah Regresi Linier Berganda. Berdasarkan hasil penelitian dapat dilihat bahwa : (1) gaya kepemimpinan berpengaruh positif signifikan terhadap semangat karyawan, (2) motivasi berpengaruh positif signifikan terhadap semangat karyawan, (3) lingkungan kerja berpengaruh positif signifikan terhadap semangat karyawan, dan (4) secara simultan gaya kepemimpinan, motivasi dan lingkungan kerja berpengaruh signifikan terhadap semangat karyawan

Kata kunci : gaya kepemimpinan, motivasi dan lingkungan kerja terhadap semangat kerja

\section{Pendahuluan}

Setiap organisasi, baik yang berorientasi pada bisnis maupun non bisnis sebaiknya selalu memberikan perhatian pada peningkatan kualitas sumber daya manusia (SDM) yang dimiliki serta tidak lupa untuk secara berkelanjutan mengembangkan kualitas SDM. 
Pengembangan kemampuan karyawan sebaiknya menjadi program prioritas karena peningkatan kualitas SDM akan diikuti oleh perkembangan perusahaan. Dalam rangka memajukan operasionalnya perusahaan hendaknya memperhatikan semangat kerja karyawan. Semangat kerja yang tinggi akan berdampak positif seperti rendahnya tingkat absensi, rendahnya turnover intention, dan kinerja yang tinggi. Semangat kerja disebabkan oleh beberapa faktor diantaranya seperti gaya kepemimpinan, motivasi dan lingkungan kerja.

Menurut Paul Hersay dan Ken Blanchard (2008:18), gaya kepemimpinan adalah upaya yang dilakukan seseorang untuk mempengaruhi orang lain untuk ikut dalam tujuan bersama. Gaya kepemimpinan tersebut meliputi proses mempengaruhi dalam menentukan tujuan organisasi, memotivasi perilaku pegawai untuk mencapai tujuan.Penelitian yang dilakukan oleh Anggraeni (2008) menunjukkan bahwa gaya kepemimpinan berpengaruh secara signifikan terhadap semangat kerja karyawan.

Untuk meningkatkan semangat kerja karyawan adapula faktor lainyang mempengaruhi semangat kerja karyawan yaitu motivasi. Menurut Wibowo (2016:321) motivasi seseorang untuk melakukan kegiatan akan muncul karena dirasakan perlu untuk memenuhi kebutuhan. Penelitian yang dilakukan oleh Purnomowati (2006) bahwa secara parsial faktor-faktor motivasi berpengaruh signifikan terhadap kinerja karyawan. Dengan menggunakan variabel moderator komitmen secara bersama-sama dan secara parsial faktor-faktor motivasi berpengaruh signifikan terhadap kinerja.

Selain gaya kepemimpinan dan motivasi kerja, dalam perusahaan harus dapat menciptakan lingkungan kerja yang kondusif untuk memberikan rasa aman kepada karyawan agar bekerja lebih optimal. Menurut Sedarmayanti (2009:26), "lingkungan kerja fisik adalah semua keadaan yang berbentuk fisik yang terdapat di sekitar tempat kerja yang dapat mempengaruhi karyawan baik secara langsung maupun tidak langsung. Penelitian yang dilakukan oleh Ferry Moulana (2017) yaitu lingkungan kerja, motivasi kerja berpengaruh terhadap kinerja karyawan. Serta motivasi kerja memediasi lingkungan kerja yang berdampak pada peningkatan kinerja karyawan.

Dinas Perhubungan atau biasa disingkat Dishub Kabupaten Gianyar, Provinsi Bali, memiliki tugas untuk menyelenggarakan urusan kebijakan perhubungan atau transportasi darat untuk Kabupaten Gianyar. Adapun fungsi dari Dishub adalah merumuskan kebijakan bidang perhubungan dalam wilayah kerjanya, kebijakan teknis bidang perhubungan, 
penyelenggaraan administrasi termasuk perizinan angkutan perhubungan, evaluasi dan laporan terkait bidang perhubungan. Pemilihan Dinas Perhubungan Kabupaten Gianyar sebagai lokasi penelitian ini karena, adanya fenomena yang terjadi pada Dishub Kabupaten Gianyar, yaitu turunnya semangat kerja karyawan diindikasikan dengan masih banyaknya karyawan yang datang terlambat. Tingkat absensi karyawan Dishub Kabupaten Gianyar dari bulan Januari sampai bulan Desember tahun 2019 cenderung naik turun setiap bulannya.

Tujuan penelitian ini adalah (1) mengetahui pengaruh gaya kepemimpinan terhadap semangat karyawan, (2) mengetahui pengaruh motivasi kerja terhadap semangat karyawan, (3) mengetahui pengaruh lingkungan kerja terhadap semangat karyawan, dan (4) mengetahui pengaruh gaya kepemimpinan, motivasi kerja dan lingkungan kerja terhadap semangat karyawan di Dinas Perhubungan Kabupaten Gianyar.

\section{Telaah Literatur Dan Hipotesis}

\section{Gaya Kepemimpinan}

Menurut Paul Hersay dan Ken Blanchard (2008:18), Gaya kepemimpinan adalah upaya yang dilakukan seseorang untuk mempengaruhi orang lain untuk ikut dalam tujuan bersama. Menurut Heidjrachman dan Husnan dalam Wijaya (2008:18), Gaya kepemimpinan adalah pola tingkah laku yang dirancang untuk mengintegrasikan tujuan organisasi dan tujuan individu untuk mencapai tujuan tertentu.

\section{Motivasi}

Menurut Wibowo (2016:321) motivasi seseorang untuk melakukan kegiatan akan muncul karena dirasakan perlu untuk memenuhi kebutuhan.Dalam hal ini apabila kebutuhannya tidak terpenuhi, motivasinya akan menurun. Motivasi menurut Kreitner dan Kinicki dalam Wibowo (2016:322) mengatakan bahwa motivasi merupakan proses psikologis yang membangkitkan dan mengarahkan perilaku pada pencapaian tujuan atau goal-directed behavior.

\section{Lingkungan Kerja}

Pengertian lingkungan kerja disini adalah segala sesuatu yang ada disekitar para pekerja dan yang dapat mempengaruhi dirinya dalam menjalankan tugas-tugas yang dibebankan, misalnya kebersihan, musik, penerangan, dan lain-lain menurut Sunyoto (2013:43). Pengertian lingkungan kerja menurut Sedarmayanti (2014:56) adalah keseluruhan alat perkakas dan bahan yang dihadapi, lingkungan sekitarnya dimana 
seseorang bekerja, metode kerjanya, serta pengaturan kerjanya baik sebagai perseorangan maupun sebagai kelompok.

\section{Semangat Kerja}

Menurut Tohardi (2002:427) semangat kerja merupakan kemampuan sekelompok orang untuk bekerjasama dengan giat dan konsekuen dalam mengejar tujuan bersama. Sedangkan semangat kerja menurut Nuridin (2017:45) adalah melakukan pekerjaan secara lebih giat, sehingga dengan demikian pekerjaan akan dapat diharapkan lebih cepat dan lebih baik. Sementara Anoraga (2012:10) menyebutkan bahwa semangat kerja adalah melakukan pekerjaan secara lebih giat sehingga pekerjaan cepat selesai dan lebih baik serta biaya perunit dapat diperkecil.

\section{Hipotesis}

1. Pengaruh Gaya Kepemimpinan Terhadap Semangat Kerja Pada Dinas Perhubungan Kabupaten Gianyar. Anggraeni (2008) Gaya Kepemimpinan merupakan norma perilaku yang digunakan oleh seseorang pada saat orang tersebut mencoba mempengaruhi perilaku orang lain seperti yang ia lihat. Pernyataan tersebut didukung oleh penelitian Waridin (2005) dan Anwar Rasyid (2008)menyatakan Gaya Kepemimpinan adalah sekumpulan ciri yang digunakan pimpinan untuk memengaruhi bawahan agar sasaran organisasi tercapai atau dapat pula dikatakan bahwa gaya kepemimpinan adalah pola perilaku dan strategi yang disukai dan sering diterapkan oleh seorang pemimpin. H1 : Diduga secara parsial Gaya Kepemimpinan berpengaruh positif dan signifikan terhadap semangat kerja karyawan pada Dinas Perhubungan Kabupaten Gianyar.

2. Pengaruh Motivasi Terhadap Semangat Kerja Pada Dinas Perhubungan Kabupaten Gianyar.

Motivasi menurut Wahyu Maulana, Nurul Alfian, dan Achmarul Fajar (2018). mengatakan bahwa motivasi merupakan proses psikologis yang membangkitkan dan mengarahkan perilaku pada pencapaian tujuan atau goal-directed behavior. Sehingga manajer perlu memahami proses psikologis ini apabila mereka ingin berhasil membina pekerja menuju pada penyelesaian sasaran organisasi.

H2 : Diduga secara parsial motivasi berpengaruh positif dan signifikan terhadap semangat kerja karyawan pada Dinas Perhubungan Kabupaten Gianyar. 
3. Pengaruh Lingkungan Kerja Terhadap Semangat Kerja Pada Dinas Perhubungan Kabupaten Gianyar.

Menurut Ferry Moulana, Bambang Swasto Sunuharyo, dan Hamidah Nayati Utami (2017)lingkungan kerja merupakan bagian komponen yang sangat penting didalam karyawan melakukan aktivitas bekerja. Dengan memperhatikan lingkungan kerja yang baik atau menciptakan kondisi kerja yang mampu memberikan motivasi untuk bekerja, maka akan membawa pengaruh terhadap kegairahan atau semangat karyawan bekerja.

H3 : Diduga secara parsial lingkungan kerja berpengaruh positif dan signifikan terhadap semangat kerja karyawan Dinas PerhubunganKabupaten Gianyar.

4. Pengaruh Gaya Kepemimpinan, Motivasi, Dan Lingkungan Kerja Terhadap Semangat Kerja Pada Dinas Perhubungan Kabupaten Gianyar.

Menurut Waridin (2005) dan Anwar Rasyid (2008) semangat kerja merupakan kemampuan sekelompok orang untuk bekerjasama dengan giat dan konsekuen dalam mengejar tujuan bersama.

H4 : Diduga secara simultan Gaya Kepemimpinan, motivasi, dan lingkungan kerja berpengaruh positif dan signifikan terhadap semangat kerja karyawan pada Dinas Perhubungan Kabupaten Gianyar.

\section{Metode Penelitian}

Penelitian ini menggunakan metode penelitian kuantitatif, yaitu penelitian empiris yang datanya berbentuk angka - angka. Dalam penelitian ini digunakan yaitu penelitian survey. Variabel yang diuji dalam penelitian ini terdiri atas tiga variabel terikat yaitu gaya kepemimpinan (X1), motivasi kerja (X2), dan lingkungan kerja (X3) dan satu variabel terikat yaitu semangat karyawan (Y).

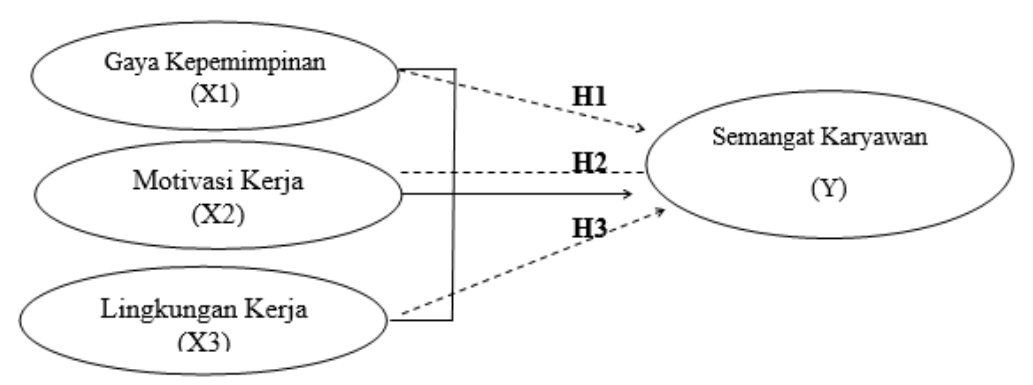

Gambar 1. Kerangka Berpikir

Populasi pada penelitian ini sebanyak 225 orang pegawai THL (Tenaga Harian Lepas) yang bekerja di Kantor Dinas Perhubungan Kabupaten Gianyar karena tidak termasuk PNS (Pegawai Negeri Sipil). Penentuan sampel dilakukan dnegan menggunakan 
Rumus Slovin sehingga diperoleh sampel sebanyak 100 orang responden dengan metode penentuan sampel menggunakan simple random sampling. Untuk mendapatkan data yang relevan dengan topik penelitian maka digunakan metode berupa observasi, wawancara, dokumentasi, kepustakaan, dan kuisioner. Dalam penelitian ini digunakan Skala Likert dengan lima pilihan jawaban yaitu sangat tidak setuju diberi bobot nilai 1, tidak setuju diberi bobot nilai 2, ragu-ragu diberi bobot nilai 3, setuju diberi bobot nilai 4, dan sangat setuju diberi bobot nilai 5. Untuk menjawab hipotesis yang diajukan maka digunakan teknik analisis regresi linear berganda untuk mengetahui arah pengaruh variabel bebas terhadap variabel serta uji parsial (uji t) untuk menjawab H1, H2, dan H3 serta uji simultan (uji F) untuk menjawab H4.

\section{Hasil Dan Pembahasan}

\section{Uji Instrumen Penelitian.}

Tabel 1. Hasil Uji Validitas dan Reliabilitas

\begin{tabular}{|c|c|c|c|c|c|}
\hline \multirow[b]{2}{*}{ Variabel } & \multicolumn{3}{|c|}{ Validitas } & \multicolumn{2}{|c|}{ Reliabilitas } \\
\hline & $\begin{array}{c}\text { Item } \\
\text { Pertanyaan }\end{array}$ & $\begin{array}{c}\text { Koefisien } \\
\text { Korelasi }\end{array}$ & Ket. & $\begin{array}{c}\text { Cronbach's } \\
\text { Alpha }\end{array}$ & Ket. \\
\hline \multirow{6}{*}{$\begin{array}{c}\text { Gaya } \\
\text { kepemimpinan } \\
\text { (X1) }\end{array}$} & $\mathrm{X} 1.1$ & 0,890 & Valid & \multirow{6}{*}{0,949} & \multirow{6}{*}{ Reliabel } \\
\hline & $\mathrm{X} 1.2$ & 0,890 & Valid & & \\
\hline & $\mathrm{X} 1.3$ & 0,903 & Valid & & \\
\hline & X1.4 & 0,899 & Valid & & \\
\hline & $X 1.5$ & 0,880 & Valid & & \\
\hline & $\mathrm{X} 1.6$ & 0,900 & Valid & & \\
\hline \multirow{5}{*}{ Motivasi (X2) } & $\mathrm{X} 2.1$ & 0,909 & Valid & \multirow{5}{*}{0,947} & \multirow{5}{*}{ Reliabel } \\
\hline & $\mathrm{X} 2.2$ & 0,914 & Valid & & \\
\hline & $\mathrm{X} 2.3$ & 0,924 & Valid & & \\
\hline & $X 2.4$ & 0,934 & Valid & & \\
\hline & $\mathrm{X} 2.5$ & 0,870 & Valid & & \\
\hline \multirow{10}{*}{$\begin{array}{c}\text { Lingkungan } \\
\text { kerja (X3) }\end{array}$} & X3.1 & 0,864 & Valid & \multirow{10}{*}{0,973} & \multirow{10}{*}{ Reliabel } \\
\hline & X3.2 & 0,909 & Valid & & \\
\hline & X3.3 & 0,903 & Valid & & \\
\hline & X3.4 & 0,939 & Valid & & \\
\hline & $\mathrm{X} 3.5$ & 0,899 & Valid & & \\
\hline & X3.6 & 0,879 & Valid & & \\
\hline & X3.7 & 0,908 & Valid & & \\
\hline & $\mathrm{X} 3.8$ & 0,907 & Valid & & \\
\hline & X3.9 & 0,889 & Valid & & \\
\hline & $\mathrm{X} 3.10$ & 0,887 & Valid & & \\
\hline \multirow{4}{*}{$\begin{array}{l}\text { Semangat } \\
\text { kerja (Y) }\end{array}$} & Y.1 & 0,873 & Valid & \multirow{4}{*}{0,905} & \multirow{4}{*}{ Reliabel } \\
\hline & Y.2 & 0,878 & Valid & & \\
\hline & Y.3 & 0,895 & Valid & & \\
\hline & Y.4 & 0,893 & Valid & & \\
\hline
\end{tabular}

Sumber : data diolah, 2020 
Berdasarkan Tabel 1, dapat dilihat bahwa seluruh indikator variabel pada penelitian ini yaitu gaya kepemimpinan, motivasi, lingkungan kerja dan semangat kerja valid karena memiliki nilai koefisien korelasi lebih dari 0,3 dan realiabel karena memiliki nilai cronbach's alpha lebih besar dari 0,60

\section{Karakteristik Responden}

Tabel 2. Karakteristik Responden

\begin{tabular}{clcc}
\hline Kategori & \multicolumn{1}{c}{ Pilihan } & Jumlah (orang) & Persentase (\%) \\
\hline \multirow{2}{*}{ Jenis } & Laki-laki & 59 & 59 \\
Kelamin & Perempuan & 41 & 41 \\
& Total & 100 & 100 \\
\hline \multirow{5}{*}{ Usia } & $<20$ tahun & 3 & 3 \\
& 20-30 tahun & 92 & 92 \\
& $30-40$ tahun & 5 & 5 \\
& Total & 100 & 100 \\
\hline \multirow{2}{*}{ Lama } & $0-5$ tahun & 97 & 97 \\
Bekerja & $6-10$ tahun & 3 & 3 \\
& Total & 100 & 100 \\
\hline \multirow{5}{*}{ Pendidikan } & SMA & 42 & 42 \\
& Akademisi/Diploma & 16 & 16 \\
& S1 & 40 & 40 \\
& S2/S3 & 2 & 2 \\
& Total & 100 & 100 \\
\hline
\end{tabular}

Sumber : data diolah, 2020

\section{Deskripsi Variabel Penelitian}

Tabel 3. Deskripsi Variabel Gaya Kepemimpinan

\begin{tabular}{|c|c|c|c|c|c|c|c|}
\hline \multirow{2}{*}{ Pernyataan } & \multicolumn{5}{|c|}{ Jawaban Responden } & \multirow{2}{*}{$\begin{array}{l}\text { Rata-rata } \\
\text { skor }\end{array}$} & \multirow{2}{*}{ Ket } \\
\hline & 1 & 2 & 3 & 4 & 5 & & \\
\hline $\begin{array}{l}\text { Tegasnya pimpinan Dishub Kabupaten Gianyar dalam } \\
\text { mengambil setiap keputusan. }\end{array}$ & 0 & 5 & 17 & 51 & 27 & 4 & Baik \\
\hline $\begin{array}{l}\text { Pimpinan Dishub Kabupaten Gianyar selalu memotivasi } \\
\text { agar tugas karyawan dapat dilakukan dengan baik. }\end{array}$ & 0 & 2 & 29 & 42 & 27 & 3,94 & Baik \\
\hline $\begin{array}{l}\text { Ketegasan pimpinan Dishub Kabupaten Gianyar dalam } \\
\text { menyampaikan informasi. }\end{array}$ & 0 & 4 & 30 & 46 & 20 & 3,82 & Baik \\
\hline $\begin{array}{l}\text { Pimpinan Dishub Kabupaten Gianyar mampu } \\
\text { mengendalikan bawahan untuk mematuhi peraturan } \\
\text { yang ada di perusahaan, bila tidak mematuhi peraturan } \\
\text { pimpinan akan memberikan sanksi yang ada. }\end{array}$ & 0 & 22 & 43 & 33 & 2 & 3,15 & CukupBaik \\
\hline $\begin{array}{l}\text { Pimpinan Dishub Kabupaten Gianyar sangat } \\
\text { bertanggung jawab terdahap bahawannya dan juga } \\
\text { perusahaan. }\end{array}$ & 0 & 7 & 30 & 48 & 15 & 3,71 & Baik \\
\hline $\begin{array}{l}\text { Pimpinan Dishub Kabupaten Gianyar selalu bisa } \\
\text { mengendalikan emosionalnya }\end{array}$ & 0 & 0 & 24 & 44 & 32 & 4,08 & Baik \\
\hline Rata-rata variabel & & & & & & 3,78 & Baik \\
\hline
\end{tabular}

Sumber : data diolah, 2020

Berdasarkan Tabel 3 diketahui persepsi responden mengenai variabel gaya kepemimpinan pada Dinas Perhubungan Kabupaten Gianyar adalah baik dengan nilai ratarata sebesar 3.78 . 
Berdasarkan Tabel 4 diketahui persepsi responden mengenai variabel motivasi pada Dinas Perhubungan Kabupaten Gianyar adalah baik dengan nilai rata-rata sebesar 3,76.

Tabel 4. Deskripsi Variabel Motivasi

\begin{tabular}{|c|c|c|c|c|c|c|c|}
\hline \multirow{2}{*}{ Pernyataan } & \multicolumn{5}{|c|}{ Jawaban Responden } & \multirow{2}{*}{$\begin{array}{l}\text { Rata- } \\
\text { rata skor }\end{array}$} & \multirow{2}{*}{ Ket } \\
\hline & 1 & 2 & 3 & 4 & 5 & & \\
\hline $\begin{array}{l}\text { Saya mendapat gaji sesuai dengan beban } \\
\text { tugas saya. }\end{array}$ & 0 & 8 & 20 & 44 & 28 & 3,92 & Baik \\
\hline $\begin{array}{l}\text { Saya merasa aman dan nyaman saat } \\
\text { bekerja di Dinas Perhubungan Kabupaten } \\
\text { Gianyar }\end{array}$ & 0 & 5 & 26 & 37 & 32 & 3,96 & Baik \\
\hline $\begin{array}{l}\text { Saya selalu mengutamakan etika dalam } \\
\text { bekerja baik dengan atasan, rekan kerja, } \\
\text { maupun peserta didik }\end{array}$ & 0 & 5 & 26 & 42 & 27 & 3,91 & Baik \\
\hline $\begin{array}{l}\text { Saya termotivasi bekerja dengan lebih baik } \\
\text { karena perusahaan memberikan } \\
\text { kesempatan promosi jabatan }\end{array}$ & 0 & 25 & 41 & 34 & 0 & 3,09 & CukupBaik \\
\hline $\begin{array}{l}\text { Saya mendapat kesempatan untuk } \\
\text { mengikuti pelatihan yang diadakan } \\
\text { perusahaan dalam } \\
\text { kemampuan bekerja }\end{array}$ & 0 & 3 & 23 & 53 & 21 & 3,92 & Baik \\
\hline & & & & & & 3,76 & Baik \\
\hline
\end{tabular}

Sumber : data diolah, 2020

Tabel 5. Deskripsi variabel Lingkungan Kerja

\begin{tabular}{|c|c|c|c|c|c|c|c|}
\hline \multirow{2}{*}{ Pernyataan } & \multicolumn{5}{|c|}{ Jawaban Responden } & \multirow{2}{*}{$\begin{array}{l}\text { Rata- } \\
\text { rata skor }\end{array}$} & \multirow{2}{*}{ Ket } \\
\hline & 1 & 2 & 3 & 4 & 5 & & \\
\hline $\begin{array}{l}\text { Penerangan menggunkan lampu maupun sinar } \\
\text { matahari pada Dinas Perhubungan Kabupaten } \\
\text { Gianyar membantu saya dalam bekerja. }\end{array}$ & 0 & 9 & 29 & 41 & 21 & 3,74 & Baik \\
\hline $\begin{array}{l}\text { Sirkulasi udara yang baik di setiap ruangan } \\
\text { Dinas Perhubungan Kabupaten Gianyar. }\end{array}$ & 0 & 9 & 34 & 26 & 31 & 3,79 & Baik \\
\hline $\begin{array}{l}\text { Saya merasa terganggu dengan suara bising saat } \\
\text { bekerja pada Dinas Perhubungan Kabupaten } \\
\text { Gianyar. }\end{array}$ & 0 & 6 & 35 & 30 & 29 & 3,82 & Baik \\
\hline $\begin{array}{l}\text { Penataan tata letak sarana dan prasarana pada } \\
\text { Dinas Perhubungan Kabupaten Gianyar } \\
\text { memepermudah saya dalam bekerja. }\end{array}$ & 0 & 11 & 29 & 32 & 28 & 3,77 & Baik \\
\hline $\begin{array}{l}\text { Dinas Perhubungan Kabupaten Gianyar } \\
\text { menjamin keamanan } \\
\text { karyawannya. }\end{array}$ & 0 & 8 & 30 & 34 & 28 & 3,82 & Baik \\
\hline $\begin{array}{l}\text { Saya selalu menjaga kebersihan disekitar } \\
\text { lingkungan Dinas Perhubungan Kabupaten } \\
\text { Gianyar }\end{array}$ & 0 & 29 & 33 & 36 & 2 & 3,11 & $\begin{array}{l}\text { Cukup } \\
\text { baik }\end{array}$ \\
\hline $\begin{array}{l}\text { Saya betanggung jawab atas semua tugas yang } \\
\text { diberikan kepada saya. }\end{array}$ & 0 & 6 & 28 & 34 & 32 & 3,92 & Baik \\
\hline $\begin{array}{l}\text { Saya bekerja sesuai dengan tugas yang } \\
\text { diberikan kepada saya. }\end{array}$ & 0 & 6 & 35 & 31 & 28 & 3,81 & Baik \\
\hline $\begin{array}{l}\text { Saya selalu menjaga komunikasi yang baik } \\
\text { dengan sesama rekan kerja maupun pimpinan } \\
\text { Dinas Perhubungan Kabupaten Gianyar. }\end{array}$ & 0 & 8 & 28 & 34 & 30 & 3,86 & Baik \\
\hline Saya mampu bekerjasama dengan tim. & 0 & 7 & 20 & 36 & 37 & 4,03 & Baik \\
\hline Rata-rata variabel & & & & & & 3,77 & Baik \\
\hline
\end{tabular}

Sumber : data diolah, 2020 
Berdasarkan Tabel 5 diketahui persepsi responden mengenai variabel lingkungan kerja pada Dinas Perhubungan Kabupaten Gianyar adalah baik dengan nilai rata-rata sebesar 3.77 .

\section{Uji Asumsi Klasik}

Berdasarkan uji normalitas yang ditampilkan pada Tabel 6, besarnya nilai Asymp. Sig. (2-tailed) adalah sebesar 0,396 yaitu lebih besar dari 0,05 yang menunjukan bahwa data terdistribusi secara normal, sehingga dapat disimpulkan bahwa model memenuhi asumsi normalitas.

Tabel 6. Hasil Uji Normalitas One-Sample Kolmogorov-Smirnov Test

\begin{tabular}{lll}
\hline & & $\begin{array}{l}\text { Unstandardized } \\
\text { Residual }\end{array}$ \\
\hline $\mathrm{N}$ & & 100 \\
\multirow{2}{*}{ Normal Parameters ${ }^{\mathrm{a}, \mathrm{b}}$} & Mean & $0,00 \mathrm{E}+00$ \\
& Std. Deviation & 197.824 .557 \\
& Absolute & .090 \\
Most Extreme Differences & Positive & .085 \\
& Negative & -.090 \\
Kolmogorov-Smirnov Z & & .898 \\
Asymp. Sig. (2-tailed) & & .396 \\
\hline
\end{tabular}

Sumber : data diolah, 2020

Berdasarkan Tabel 7, seluruh variabel bebas memiliki nilai tolerance $>0,10$, begitu juga dengan hasil perhitungan nilai VIF, seluruh variabel memiliki nilai VIF $<10$. Hal ini berarti bahwa pada model regresi yang dibuat tidak terdapat gejala multikolinearitas.

Tabel 7. Hasil Uji Multikolinearitas

\begin{tabular}{|c|c|c|c|c|c|c|c|c|}
\hline & \multirow[t]{2}{*}{ Model } & \multicolumn{2}{|c|}{$\begin{array}{l}\text { Unstandardized } \\
\text { Coefficients }\end{array}$} & \multirow{2}{*}{$\begin{array}{c}\begin{array}{c}\text { Standardized } \\
\text { Coefficients }\end{array} \\
\text { Beta }\end{array}$} & \multirow[t]{2}{*}{$\mathrm{T}$} & \multirow[t]{2}{*}{ Sig. } & \multicolumn{2}{|c|}{ Collinearity Statistics } \\
\hline & & $\mathrm{B}$ & Std. Error & & & & Tolerance & VIF \\
\hline \multirow{4}{*}{1} & (Constant) & 2.608 & 1.273 & & 2.049 & .043 & & \\
\hline & Gaya kepemimpinan & .193 & .054 & .287 & 3.568 & .001 & .777 & 1.287 \\
\hline & Motivasi & .234 & .070 & .311 & 3.348 & .001 & .583 & 1.714 \\
\hline & Lingkungan kerja & .099 & .031 & .290 & 3.213 & .002 & .617 & 1.622 \\
\hline
\end{tabular}

Sumber : data diolah, 2020

Berdasarkan Tabel 8, masing-masing model memiliki nilai signifikansi lebih besar dari 0,05. Berarti didalam model regresi ini tidak terjadi heteroskedastisitas.

Tabel 8. Hasil Uji Heteroskedastisitas

\begin{tabular}{|c|c|c|c|c|c|c|}
\hline \multirow{2}{*}{\multicolumn{2}{|c|}{ Model }} & \multicolumn{2}{|c|}{$\begin{array}{l}\text { Unstandardized } \\
\text { Coefficients }\end{array}$} & \multirow{2}{*}{$\begin{array}{c}\text { Standardized } \\
\text { Coefficients } \\
\text { Beta } \\
\end{array}$} & \multirow[t]{2}{*}{$\mathrm{T}$} & \multirow[t]{2}{*}{ Sig. } \\
\hline & & $\mathrm{B}$ & Std. Error & & & \\
\hline \multirow{4}{*}{1} & (Constant) & 2.783 & .889 & & 3.129 & .002 \\
\hline & Gaya kepemimpinan & -.012 & .038 & -.036 & -.318 & .751 \\
\hline & Motivasi & -.055 & .049 & -.148 & -1.122 & .265 \\
\hline & Lingkungan kerja & -.002 & .022 & -.015 & -.114 & .910 \\
\hline
\end{tabular}

Sumber : data diolah, 2020 


\section{Analisis Regresi Linear Berganda}

Pengujian hipotesis dilakukan untuk menguji hipotesis yang diajukan. Hipotesis yang diajukan dalam penelitian ini terkait pengaruh gaya kepemimpinan, motivasi, lingkungan kerja terhadap semangat kerja. Analisis regresi berganda dipilih untuk menganalisis pengujian hipotesis dalam penelitian ini.

Tabel 9. Hasil Analisis Regresi Linear Berganda

\begin{tabular}{|c|c|c|c|c|c|c|}
\hline \multirow{2}{*}{\multicolumn{2}{|c|}{ Model }} & \multicolumn{2}{|c|}{$\begin{array}{c}\text { Unstandardized } \\
\text { Coefficients }\end{array}$} & \multirow{2}{*}{$\begin{array}{c}\text { Standardized } \\
\text { Coefficients }\end{array}$} & \multirow[t]{2}{*}{$\mathrm{t}$} & \multirow[t]{2}{*}{ Sig. } \\
\hline & & $\mathrm{B}$ & Std. Error & & & \\
\hline \multirow{4}{*}{1} & (Constant) & 2.608 & 1.273 & & 2.049 & .043 \\
\hline & Gaya kepemimpinan & .193 & .054 & .287 & 3.568 & .001 \\
\hline & Motivasi & .234 & .070 & .311 & 3.348 & .001 \\
\hline & Lingkungan kerja & .099 & .031 & .290 & 3.213 & .002 \\
\hline
\end{tabular}

Sumber : data diolah, 2020

Berdasarkan Tabel 9 dapat diketahui persamaan regresinya menjadi $\quad \mathrm{Y}=\beta_{0}+$ $\beta_{1} X_{1}+\beta_{2} X_{2}+\beta_{3} X_{3}+\mu$. Dari persamaan diatas maka dapat dibuat persamaan regresi penelitian ini adalah $: \mathrm{Y}=2,608+0,193 \mathrm{X} 1+0,234 \mathrm{X} 2+0,099 \mathrm{X} 3$. Interprestasi dari koefisien regresi :

$\beta_{0}=2,608$ secara statistik menunjukan bahwa nilai constant sebesar 1,204 yang artinya apabila variabel gaya kepemimpinan (X1), motivasi (X2) dan lingkungan kerja (X3) tidak mengalami perubahan maka semangat kerja akan sebesar konstan 2,608 .

$\beta_{1}=0,193$ secara statistik menunjukkan ada pengaruh positif dan signifikan antara variabel gaya kepemimpinan (X1) terhadap semangat kerja (Y) sebesar 0,193 yang artinya setiap terjadi kenaikan (adanya) gaya kepemimpinan sebesar satu satuan maka akan menyebabkan meningkatanya semangat kerja sebesar 0,193 satuan dengan syarat variabel lain diasumsikan sama tidak mengalami perubahan.

$\beta_{2}=0,234$ secara statistik menunjukkan ada pengaruh positif dan signifikan antara variabel motivasi (X2) terhadap semangat kerja (Y) sebesar 0,234 yang artinya setiap terjadi kenaikan (adanya) kualitas prouk sebesar satu satuan maka akan menyebabkan meningkatanya semangat kerja sebesar 0,234 satuan dengan syarat variabel lain diasumsikan sama tidak mengalami perubahan.

Berdasarkan Tabel 9 maka dapat dikemukakan hasil uji signifikansi parsial (uji t) dalam menjawab Hipotesis 1 (H1), hipotesis 2 (H2) dan hipotesis 3 (H3) sebagai berikut : 
1. Pengaruh gaya kepemimpinan terhadap semangat kerja pada Dinas Perhubungan Kabupaten Gianyar

Dari hasil penelitian diketahui adanya pengaruh positif gaya kepemimpinan terhadap keputusan pembelia. Hal ini dibuktikan dengan nilai $t_{\text {hitung }}=3,568$ dibandingkan dengan nilai $\mathrm{t}_{\text {tabel }}=1,984$ dan nilai signfikansi $=0.001$ dengan nilai $\alpha=0,05$, maka ternyata nilai $t_{\text {hitung }}$ lebih besar dari nilai $t_{\text {tabel, }}$ dan nilai signifikansi lebih kecil dari nilai $\alpha$. Ini berarti bahwa secara statistik untuk uji satu sisi pada taraf kepercayaan $(\alpha)=$ $5 \%$, secara parsial variabel gaya kepemimpinan (X1) berpengaruh positif dan signifikan terhadap semangat kerja (Y). Artinya jika terjadi peningkatan pada variabel gaya kepemimpinan (X1) maka akan meningkatkan semangat kerja (Y). Dengan demikian hipotesis yang menyatakan bahwa gaya kepemimpinan (X1) berpengaruh positif dan signifikan secara parsial terhadap semangat kerja (Y) diterima. Hasil penelitian ini juga mendukung penelitian sebelumnya yang dilakukan oleh Anggraeni (2008) menyatakan bahwa gaya kepemimpinan berpengaruh positif terhadap semangat kerja.

2. Pengaruh motivasi terhadap semangat kerja pada Dinas Perhubungan Kabupaten Gianyar

Dari hasil penelitian diketahui adanya pengaruh positif motivasi terhadap keputusan pembelia. Hal ini dibuktikan dengan nilai thitung $=3,348$ dibandingkan dengan nilai tabel $=1,984$ dan nilai signfikansi $=0.001$ dengan nilai $\alpha=0,05$, maka ternyata nilai $t_{\text {hitung }}$ lebih besar dari nilai $t_{\text {tabel, }}$ dan nilai signifikansi lebih kecil dari nilai $\alpha$ Ini berarti bahwa secara statistik untuk uji satu sisi pada taraf kepercayaan $(\alpha)=5 \%$, secara parsial variabel motivasi (X2) berpengaruh positif dan signifikan terhadap semangat kerja (Y). Artinya jika terjadi peningkatan pada variabel motivasi (X2) maka akan meningkatkan semangat kerja (Y). Dengan demikian hipotesis yang menyatakan bahwa motivasi (X2) berpengaruh positif dan signifikan secara parsial terhadap semangat kerja (Y) diterima. Hasil penelitian ini juga mendukung penelitian sebelumnya yang dilakukan oleh Ferry Moulana, Bambang Swasto Sunuharyo, dan Hamidah Nayati Utami (2017) menyatakan bahwa motivasi berpengaruh positif terhadap semangat kerja. 
3. Pengaruh lingkungan kerja terhadap semangat kerja pada Dinas Perhubungan Kabupaten Gianyar

Dari hasil penelitian diketahui adanya pengaruh positif lingkungan kerja terhadap keputusan pembelia. Hal ini dibuktikan dengan nilai $t_{\text {hitung }}=3,213$ dibandingkan dengan nilai $\mathrm{t}_{\text {tabel }}=1,984$ dan nilai signfikansi $=0.002$ dengan nilai $\alpha=0,05$, maka ternyata nilai $t_{\text {hitung }}$ lebih besar dari nilai $t_{\text {tabel, }}$ dan nilai signifikansi lebih kecil dari nilai $\alpha$. Ini berarti bahwa secara statistik untuk uji satu sisi pada taraf kepercayaan $(\alpha)=$ $5 \%$, secara parsial variabel lingkungan kerja (X3) berpengaruh positif dan signifikan terhadap semangat kerja (Y). Artinya jika terjadi peningkatan pada variabel lingkungan kerja (X3) maka akan meningkatkan semangat kerja (Y). Dengan demikian hipotesis yang menyatakan bahwa lingkungan kerja (X3) berpengaruh positif dan signifikan secara parsial terhadap semangat kerja (Y) diterima. Hasil penelitian ini juga mendukung penelitian sebelumnya yang dilakukan oleh Anwar Rasyid (2008) menyatakan bahwa lingkungan kerja berpengaruh positif terhadap semangat kerja.

\section{Uji Signifikansi Simultan (Uji F)}

Uji f-test digunakan untuk menguji $\mathrm{H} 4$, yaitu pengaruh gaya kepemimpinan (X1), motivasi (X2) dan lingkungan kerja (X3) secara simultan berpengaruh terhadap semangat $\operatorname{kerja}(\mathrm{Y})$.

\begin{tabular}{rlrrrrr}
\multicolumn{7}{c}{ Tabel 10, Hasil uji F } \\
ANOVA $^{\mathbf{a}}$
\end{tabular}

Sumber : data diolah, 2020

Dari hasil penelitian diketahui adanya pengaruh secara simultan variabel gaya kepemimpinan, motivasi dan lingkungan kerja terhadap semangat kerja. Hal ini dibuktikan dengan nilai $F_{\text {hitung }}=34,288$ dibandingkan dengan nilai $F_{\text {tabel }}=2,70$ dan nilai signfikansi $=$ 0.000 dengan nilai $\alpha=0,05$. Maka ternyata nilai $\mathrm{F}_{\text {hitung }}$ lebih besar dari nilai $\mathrm{F}_{\text {tabel, }}$ dan $\mathrm{t}_{\text {hitung }}$ dan nilai signifikansi lebih kecil dari nilai $\alpha$, sehingga berada pada daerah penolakan $\mathrm{H} 0$. Dengan demikian H0 ditolak dan H4 diterima. Ini berarti bahwa secara statistik untuk uji satu sisi pada taraf kepercayaan $(\alpha)=5 \%$, secara simultan gaya kepemimpinan (X1), motivasi (X2) dan lingkungan kerja (X3) berpengaruh signifikan terhadap semangat kerja (Y). Artinya jika terjadi peningkatan pada variabel simultan gaya kepemimpinan (X1), 
motivasi (X2) dan lingkungan kerja (X3) maka akan meningkatkan semangat kerja (Y). Dengan demikian hipotesis yang menyatakan bahwa simultan simultan gaya kepemimpinan (X1), motivasi (X2) dan lingkungan kerja (X3) berpengaruh signifikan secara simultan terhadap semangat kerja (Y) teruji kebenarannya. Hal ini berarti semakin baik gaya kepemimpinan, motivasi dan lingkungan kerja maka akan meningkatkan semangat kerja pada Dinas Perhubungan Kabupaten Gianyar.

\section{Penutup}

\section{Simpulan}

1. Gaya kepemimpinan berpengaruh positif dan signifikan secara parsial terhadap semangat kerja pada Dinas Perhubungan Kabupaten Gianyar. Hal ini dapat dibuktikan melalui hasil uji signifikan parsial (uji t-test) dimana diperoleh nilai thitung kepemimpinan $=3,568$ dan nilai signifikansi $=0.001$, sehingga $\mathrm{H} 1$ diterima.

2. Motivasi berpengaruh positif dan signifikan secara parsial terhadap semangat kerja pada Dinas Perhubungan Kabupaten Gianyar. Hal ini dapat dibuktikan melalui hasil uji signifikan parsial (uji t-test) dimana diperoleh nilai $t_{\text {hitung }}$ tunjangan $=3,348$ dan nilai signifikansi $=0.001$, sehingga $\mathrm{H} 0$ ditolak dan $\mathrm{H} 1$ diterima.

3. Lingkungan kerja berpengaruh positif dan signifikan secara parsial terhadap semangat kerja pada Dinas Perhubungan Kabupaten Gianyar. Hal ini dapat dibuktikan melalui hasil uji signifikan parsial (uji t-test) dimana diperoleh nilai $t_{\text {hitung }}$ tunjangan $=3,213$ dan nilai signifikansi $=0.002$, sehingga $\mathrm{H} 0$ ditolak dan $\mathrm{H} 1$ diterima.

4. Gaya kepemimpinan, motivasi dan lingkungan kerja berpengaruh secara simultan terhadap semangat kerja pada Dinas Perhubungan Kabupaten Gianyar. Hal ini dapat dibuktikan melalui hasil uji signifikan simultan (uji f-test) menunjukkan dari hasil nilai $\mathrm{F}_{\text {hitung }}=34,288$ dan nilai signfikansi $=0.000$.

\section{Saran}

1. Dari pernyataan mengenai gaya kepemimpinan. Pimpinan Dishub Kabupaten Gianyar diharapkan selalu tegas dalam mengendalikan bawahan untuk mematuhi peraturan yang ada di perusahaan, dan memberikan sanksi terhadap pegawai yang tidak mematuhi peraturan.

2. Dari pernyataan mengenai motivasi. Saya termotivasi bekerja dengan lebih baik karena perusahaan memberikan kesempatan promosi jabatan memiliki nilai rata-rata terendah. 
Melihat hasil penelitian tersebut, Dishub Kabupaten Gianyar diharapkan selalu bersikap adil memberikan kesempatan promosi kepada pegawai.

3. Dari pernyataan mengenai lingkungan kerja. Pernyataan saya selalu menjaga kebersihan disekitar lingkungan Dinas Perhubungan Kabupaten Gianyar memiliki nilai rata-rata terendah, melihat hasil penelitian tersebut Dinas Perhubungan Kabupaten Gianyar memberikan bimbingan kepada pegawai agar selalu menjaga kebersihan lingkungan.

4. Dari pernyataan mengenai semangat kerja. Pernyataan saya adalah orang yang displin dalam bekerja pada Dishub Kabupaten Gianyar memiliki nilai rata-rata terendah, melihat hasil penelitian tersebut Dinas Perhubungan Kabupaten Gianyar hendaknya memberikan teguran atau sanksi kepada karyawan yang tidak disiplin.

5. Bagi peneliti selanjutnya, agar dapat meneliti dan mengkaji lebih dalam faktor-faktor lain yang tidak diteliti dalam penelitian ini yang dapat mempengaruhi semangat kerja selain gaya kepemimpinan, motivasi dan lingkungan kerja. Agar nantinya dapat mengetahui tindakan apa yang harus dilakukan oleh Dinas Perhubungan Kabupaten Gianyar untuk meningkatkan kinerja karyawan.

\section{Referensi}

A Margono, Gunthar Riady, 2014, Pengaruh Kesesuaian Pegawai terhadap Kinerja Pegawai pada Dinas Perkebunan Provinsi Kalimantan Timur, Journal Administrative Reform, ISSN 000-000, ar, mian-fisip-ummul, ac.id.

Amrul, Sadat S dan Nasir, Moch, Pengaruh Gaya Kepemimpinan dan Ketidakpastian Lingkungan terhadap Hubungan antara Partisipasi Penganggaran dengan Senjangan Anggaran, Simposium Nasional Akuntansi 5, Semarang tanggal 5 - 6 September 1998.

Anggraini Sukmawati. 2013. "Analisis Beban Kerja Sumber Daya Manusia dalam Aktivitas Produksi Komoditi Sayuran Selada". Jurnal Manajemen dan Organisasi,Vol IV,No.2.

Anggraini, Lunta Maya. 2008. Pengaruh Karakteritik Individu Dan Faktor Lingkungan Terhadap Kepuasan Kerja Pada Dinas Pendidikan Kebumen

Annisa, N. (2015). "Pengaruh Lingkungan Kerja Terhadap Semangat Kerja Pegawai di Kantor Kelurahan Air Putih Samarinda", E-jurnal Administrasi Negara, 3 (5), ISSN: 1452-1463

Anoraga, p. (2012). Psikologi Kerja. jakarta : Rineka Cipta

Arep, Ishak dan Hendri Tanjung. (2003). Manajemen Motivasi, Penerbit PT.Gramedia Widiasarana Indonesia, Jakarta

Aribowo, Risky Novianto. (2011). Pengaruh Kepemimpinan, Motivasi dan Lingkungan Kerja Fisik TerhadapKinerja Karyawan Pada CV. Karya Mina Putra Rembang Devisi Kayu. E-jurnal managemen. Universitas Diponegoro. 
Arif, Amir 2009. Pengaruh Lingkungan Kerja Terhadap Semangat Kerja Karyawan Bagian Produksi Pada Ud Logam Jaya di Tambar Jogoroto. Jurnal NasionalE. doc library.

Azwar. 2002. Reliabilitas dan Validitas. Yogyakarta: Pustaka Pelajar.

Basuki, Kustiadi dan Saputra, Gery Adhes. 2017. Pengaruh Lingkungan Kerja Dan Sistem Reward Terhadap Kinerja Karyawan Di Moderasi Disiplin Kerja (Studi Pada Pt. Mitra Inovasi Gemilang) Di Jakarta. Jurnal Online

Dwipayana, Made Agus .2013. Pengaruh Disiplin Kerja, Motivasi dan Gaya Kepemimpinan Terhadap Kinerja Karyawan Pada Percetakan Sabdha Jaya di Denpasar. E-jurnal Ekonomi dan Bisnis. Universitas Udayana, Bali

Ferry Moulana, Bambang Swasto Sunuharyo, Hamidah Nayati Utami 2017. Pengaruh Lingkungan Kerja Terhadap Kinerja Karyawan Melalu Variabel Mediator Motivasi Kerja. Jurnal Administrasi Bisnis Vol. 44 No.1 Maret 2017.

Fiedler, F.E,(1996), A Theory of Leadership Effectiveness, New York: Mc Graw-Hill

Ghozali, Imam. 2005. Aplikasi Analisis Multivariate dengan SPSS. Semarang: Badan Penerbit UNDIP.

Hersey, Paul dan Kenneth. H. Blanchard, Kepemimpinan Birokrasi, Terjemahaan Harbani Pasolong, (2008), Alfabeta, Bandun (2014), Manajemen Perilaku Organisasi, Jakarta: Erlangga.

Hasibuan,S.P,Melayu, (2010), Manajemen Sumber Daya Manusia, PT. Bumi Aksara, Jakarta.

.2007. Manajemen Sumber Daya Manusia, cetakan kesembilan, Jakarta: PT Bumi Aksara

Kartono, Kartini. Pemimpin dan Kepemimpinan. Jakarta: Raja Grafindo Persada, 1996.

Kotler, Philip. 2012. Manajemen Pemasaran, Analisa perencanaan, Implementasi dan Kontrol, Jakarta, Erlangga.

Meta, Nandha. 2013. Pengaruh Disiplin Kerja dan Kepemimpinan Terhadap Kinerja Karyawan Pada PT. Pustaka Rizki Putra Semarang. Tesis. E-jurnal Ilmu Sosial dan Politik. Universitas Diponegoro Semarang

Miftah Thoha. 2013. Perilaku organisasi konsep dasar dan implikasinya. Jakarta : PT. Raja Grafindo Persada.

Murni Indrayani, 2014), Pengaruh Gaya Kepemimpinan, Kepuasan Kerja dan Komitmen Organisasi terhadap Kinerja Pegawai pada Kantor Sekretariat Daerah Kabupaten Pangkajene dan Kepulauan, Jurnal

Nitisemito. 1996. Manajemen Personalia ( Manajemen Sumber Daya Manusia). Kudus: Ghalia Indonesia

Nugroho, Satyo Adi.2011.Pengaruh Motivasi terhadap Semangat Kerja Karyawan. Skripsi, E-jurnal Ekonomi. Universitas Brawijaya.

Oktavianti, Tika. 2011. Pengaruh Lingkungan Kerja Terhadap Semangat Kerja. E-jurnal managemen. Universitas Brawijaya.

Pasaribu (2015) "Pengaruh Kepemimpinan, Lingkungan Kerja Dan Iklim Organisasi Terhadap Semangat Kerja Karyawan Pada PT. Multisarana agro lestari pekanbaru". E-jurnal Administrasi .Jom FEKON Vol. 2 No 2

Prakoso, R. D., Astuti, E. S., \& Ruhana, I. (September 2004). Pengaruh Lingkungan Kerja terhadap Motivasi Kerja dan Kinerja Karyawan. Jurnal Administrasi Bisnis (JAB) Vol.14 No.2

Purnomowati, endang, 2006, Majalah Ekonomi Jakarta; Tahun XVI No.3 
Rasyid, Anwar. 2008. Pengaruh Gaya Kepemimpinan Terhadap Semangat Kerja Karyawan Pada Perusahaan Knalpot Roda Jaya Malang: Jurusan Manajemen Universitas Merdeka Malang. (online) (http://library.unmer.ac.id/index.php?p=show_detail\&id=21607 diakses pada 1 Oktober 2014)

Regina Aditya Reza. 2010. Pengaruh Gaya Kepemimpinan, Motivasi, dan Disiplin Kerja terhadap Kinerja Karyawan PT. Sinar Santosa Perkasa Banjarnegara. E-jurnal Managemen Universitas Diponegoro.

Rivai. 2014. Kepemimpinan dan Perilaku Organisasi. Jakarta: PT. Raja Grafindo Persada

Robbins, S.P. 1994. Perilaku organisasi. Jakarta : Prenhallindo. .2007. "Perilaku Organisasi” edisi 12. Jakarta : salemba 4. .2013, Manajemen. Edisi ke 7. Jilid 2. Edisi Bahasa Indonesia. Indeks, Jakarta

Saifuddin Azwar, (2012) Reliabilitas dan Validitas, Yogyakarta, Pustaka Pelajar.

Sedarmayanti. 2004. Sumber Daya Manusia dan Produktivitas Kerja. Bandung: Mandar Maju.

Simbolon, Julius, dan Nuridin. (2017). Pengaruh K3 dan Lingkungan Kerja Terhadap Kinerja Karyawan (Studi pada PT Dwi Lestari Nusantara). Jurnal Manajemen Bisnis Krisnadwipayana.

Stoner, James A. F. 1996. Manajemen. Jakarta: PT. Prenhalindo

Sugiyono, (2013), Metode Penelitian Bisnis. Bandung: Alfabeta. 2010. Metode Penelitian Bisnis. Jakarta : Alfabeta.

.2011. Metode Penelitian Kuantitatif, Kualitatif dan $R \&$ D . Bandung: Alfabeta.

Sukmawati Feriza. 2008 "Pengaruh Kepemimpinan Lingkungan Kerja Fisik dan Kompensasi Terhadap Semangat Kerja Karyawan di PT Pertamina (Persero) UPMS III Terminal (Transit Utama Balongan Indramayu”. Jurnal Eksklusif Volume 3. Diunduh tanggal 13 Agustus 2013.

Sutikno, M. Sobry.2014. Pimpinan dan Gaya Kepemimpinan (Edisi Pertama), Lombok: Holistica.

Sutrisno. 2014. Manajemen Sumber Daya Manusia. Penerbit: Jakarta, Kencana.

Tampubolon, Biatna. D. 2007. Analisis Faktor Gaya Kepemimpinan Dan Faktor Etos Kerja Terhadap Kinerja Pegawai Pada Organisasi Yang Telah Menerapkan SNI 19-9001-2001. Jurnal Standardisasi. No 9.

Tohardi, Ahmad. 2002. Pemahaman Praktis Manajemen Sumber Daya Manusia. Bandung: Mandar Maju

Tyssen, Theodore. 2013. Bisnis dan Manajemen Buku Petunjuk bagi Manajer Pemula, Alih bahasa Hadyana. Jakarta.

Umar, Husein. 2003. "Metode Riset Akuntansi Terapan”. Jakarta: Ghalia Indonesia

Utomo, B. 2002. Menentukan Faktorfaktor Kepuasan Kerja dan Tingkat Pengaruh Kepuasan Kerja terhadap Loyalitas Karyawan PT P.Jurnal Manajemen \& Kewirausahaan. Vol. 7 (2).

Wibowo (2016). Manajemen Kinerja. Jakarta: PT. Raja Grafindo Persada.

Wibowo, N. R. (2016). Hubungan Antara Locus of Control Internal dan Self Efficacy dengan Kepuasan Kerja Karyawan Departemen Spinning PT. Daya Manunggal. Skripsi

Wibowo, Untung.2016. Analisa Pengaruh gaya Kepemimpinan Dan Kepuasan Kerja Terhadap Kinerja Bawahan (Studi Empisi Pada Perguruan Tinggi Swasta Di Kota Semarang), Jurnal Studi Manajemen Dan Organisasional, Vol. 1 No. 2 Desember Fakultas Ekonomi STIE PENA, Semarang. 
Wirawan, Nata. 2016. Cara Mudah Memahami Statistik 2 (Statistik Infrensia) Untuk Ekonomi dan Bisnis. Edisi Ketiga. Denpasar: Keraras Emas

Wirawan. 2015. Manajemen Sumber Daya Manusia Indonesia: Teori, Psikologi, Hukum Ketenagakerjaan, Aplikasi dan Penelitian: Aplikasi dalam Organisasi Bisnis, Pemerintahan dan Pendidikan, Jakarta: PT Raja Grafindo Persada.

Wursanto, Drs. Ig, 2003, Dasar-Dasar Ilmu Organisasi, Andi Offset, Yogyakarta. 